\title{
Laboreal
}

Volume 13 NN$^{\circ} 2$ | 2017

Varia

\section{Fiabilização das decisões na sala de comando de uma central nuclear: o papel da argumentação na resolução coletiva de problemas}

Fiabilización de las decisiones en la sala de control de una central nuclear: el papel de la argumentación en la resolución colectiva de problemas

Fiabilisation des décisions de conduite en salle de commande d'une centrale nucléaire : le rôle de l'argumentation dans la résolution collective de problèmes Reliability in the decisions taken in the control room of a nuclear plant: the role of argumentation in the collective problems resolution

Johanna Mérand

\section{OpenEdition}

\section{Journals}

Edição electrónica

URL: http://journals.openedition.org/laboreal/338

DOI: $10.4000 /$ laboreal.338

ISSN: 1646-5237

Editora

Universidade do Porto

Refêrencia eletrónica

Johanna Mérand, « Fiabilização das decisões na sala de comando de uma central nuclear: o papel da argumentação na resolução coletiva de problemas », Laboreal [Online], Volume 13 №2 | 2017, posto online no dia 01 dezembro 2017, consultado o 25 setembro 2020. URL : http://

journals.openedition.org/laboreal/338; DOI : https://doi.org/10.4000/laboreal.338

Este documento foi criado de forma automática no dia 25 setembro 2020.

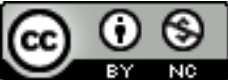

Laboreal está licenciado com uma Licença Creative Commons - Atribuição-NãoComercial 4.0 Internacional. 


\section{Fiabilização das decisões na sala de comando de uma central nuclear: o papel da argumentação na resolução coletiva de problemas}

Fiabilización de las decisiones en la sala de control de una central nuclear: el papel de la argumentación en la resolución colectiva de problemas

Fiabilisation des décisions de conduite en salle de commande d'une centrale nucléaire : le rôle de l'argumentation dans la résolution collective de problèmes Reliability in the decisions taken in the control room of a nuclear plant: the role of argumentation in the collective problems resolution

Johanna Mérand

\section{REFERÊNCIA}

Mérand, J. (2016). Fiabilisation des décisions de conduite en salle de commande d'une centrale nucléaire: le rôle de l'argumentation dans la résolution collective de problèmes. Thèse de doctorat en Ergonomie. Université Paris-Sud XI, Orsay.

\section{NOTA DO EDITOR}

http://dx.doi.org/10.15667/laborealxiii0217jmes

Manuscrito recebido em: agosto/2016

Aceite após peritagem: novembro/2017

Júri de tese: Pierre Falzon (Presidente); Françoise Darses e Cecilia de la Garza

(Orientadores); Nicolas Ambrosi, Christine Chauvin e Jean-François Vautier (Arguentes) 


\section{Contexto industrial}

1 A tese incide na resolução coletiva de problemas no controlo de situações acidentais de um sistema dinâmico e complexo, de alto risco. Inscreve-se num projeto de conceção de uma sala de controlo de um novo reator nuclear, levado a cabo por equipas multidisciplinares da EDF. Este programa visa avaliar a ligação entre o humano, os procedimentos de controlo, as interfaces humano-máquina e a organização de equipa, antes do lançamento do reator (De La Garza, Labarthe, \& Graglia, 2012; Labarthe \& De La Garza, 2011). Analisaram-se duas organizações de equipa de controlo, ao longo de duas ações de avaliação sucessivas: uma organização composta por cinco operadores (orga-5), idêntica às já existentes nas instalações de produção atuais francesas, e uma nova organização, composta por quatro operadores (orga-4). A tese interessa-se particularmente pelo impacto destas modalidades organizacionais sobre os processos coletivos de resolução de problemas, ou seja, quando os operadores constroem uma nova representação do estado da instalação e/ou ajustam o procedimento de controlo da situação.

\section{Quadro teórico}

Os ambientes dinâmicos de alto risco, como as centrais nucleares, impõem condicionalismos muito particulares na atividade cognitiva de resolução de problemas. Estas especificidades foram inúmeras vezes descritas na literatura e integram modelos mais amplos de controlo e de supervisão de um processo dinâmico (Hoc \& Amalberti, 1995; Klein \& Klinger, 1991; Rasmussen, 1986; Vicente, Mumaw, \& Roth, 2004).

3 Nestes ambientes de alto risco, a complexidade do sistema técnico e a gravidade das potenciais consequências de um erro são grandes, sobretudo num contexto incidental ou acidental. Todavia, numa central nuclear, as margens temporais são, de um modo geral, suficientemente grandes para que, face a um problema, a equipa consiga iniciar processos coletivos aprofundados de compreensão e tratamento do problema em questão. Estas interações no seio da equipa assentam, em grande medida, na comunicação verbal. Nestas situações de resolução coletiva de problemas, os operadores recolhem, trocam, confrontam e integram informações. Em suma, cooperam para construir um modelo mental partilhado da situação (Cannon-Bowers, Salas, \& Converse, 1993) sobre o qual se baseiam as suas decisões.

4 O quadro teórico da argumentação, há muito estabelecido em psicolinguística, é particularmente propício ao estudo do conteúdo e da articulação das comunicações aquando da resolução coletiva de problemas. De acordo com este quadro, argumentar consiste em convencer o outro da pertinência da sua tese recorrendo a asserções ou a argumentos fundamentados, num contexto de incerteza (Breton, 2006; Oléron, 1996; Perelman \& Olbrechts-Tyteca, 1958/2008). A argumentação tem uma função dupla (Champaud, 1994; Darses, 2006; Nussbaum, 2008). É cooperativa. A prossecução de um objetivo comum fomenta o desenvolvimento de interações construtivas ao longo das quais são elaborados conjuntamente novos sentidos ou novas soluções a partir dos contributos de cada um (Baker, 1999). É também dialética, já que se opõem dois pontos de vista. Refutar, contestar, questionar, duvidar e avaliar mediante o fornecimento de elementos de apoio, permite provar a validade das propostas e dos argumentos 
apresentados pelos outros membros do grupo (Rieke, Sillars, \& Peterson, 2005). Esta função dupla torna, assim, a argumentação um processo potencial de fiabilização das tomadas de decisão, nomeadamente aquando da resolução de problemas.

\section{Problemática e organização da tese}

Defende-se como tese que os fluxos de comunicação no seio da equipa e a atividade argumentativa que os membros desenvolvem aquando da resolução coletiva de problemas influenciam a qualidade dos diagnósticos elaborados e das tomadas de decisão. $O$ sentido da situação e o plano de ação seriam construídos e adaptados à medida da interação verbal pela apresentação de argumentos e contra-argumentos baseados nos conhecimentos técnicos, nos condicionalismos situacionais ou ainda nas exigências organizacionais. As modalidades organizacionais, como a distribuição e atribuição de funções ao pessoal, teriam um impacto mais ou menos favorável na implementação de processos argumentativos destinados a fiabilizar as tomadas de decisão coletivas.

6 Estas questões foram formuladas e investigadas ao longo de uma abordagem em quatro etapas, correspondendo cada uma a um estudo empírico (cf. Figura 1 - pág. seguinte).

7 As etapas 1 e 2 conduziram à construção da problemática e à definição das opções concetuais e metodológicas para o tratamento dos dados das etapas seguintes. Estas duas etapas consistem em análises exploratórias da atividade dos operadores que constituem a nova organização de equipa (orga-4) que não dispõe de equivalente atual nas instalações de produção francesas. Descrevemo-las sucintamente na secção 5. As etapas 3 e 4 instruem a problemática, mediante o exame dos fluxos de comunicação (etapa 3) e da atividade argumentativa (etapa 4) das equipas aquando da resolução coletiva de problemas e o respetivo impacto sobre o desempenho das equipas. Descrevemo-las mais pormenorizadamente na seç̧ão 6.

8 Todas estas etapas baseiam-se em cenários realistas de simulação de condução do processo em situações incidentais/acidentais. Os cenários são representados por futuras equipas de condução num simulador em escala completa da sala de comando. 


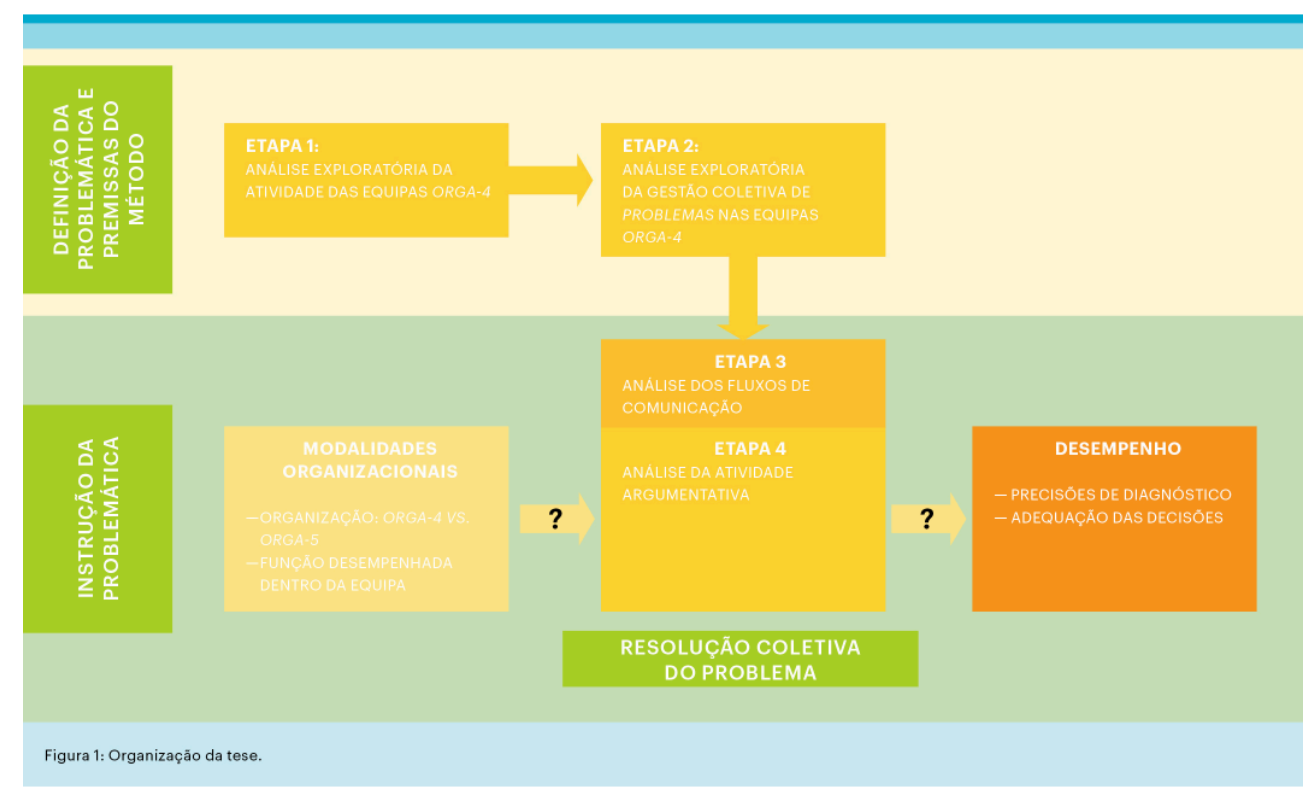

\section{População de estudo}

As funções desempenhadas pelos operadores nas equipas orga-4 e orga-5 são relativamente idênticas.

- operador responsável das operações de controlo (op) realiza as ações de operação. Esta função é desempenhada por um único operador nas equipas orga-4 e por dois operadores nas equipas orga-5.

- supervisor (sup) controla a devida realização destas ações, antecipa as ações de controlo e assegura que a estratégia de operação seja adequada em relação ao estado da instalação.

- chefe da exploração (ce), responsável da equipa, controla a coerência entre a estratégia da operação em curso e o estado da instalação. Ele assegura a interface com o posto de comando da direção de gestão da crise.

- engenheiro de segurança (es) efetua um controlo diversificado e independente do estado da instalação.

Todos os operadores que desempenham a função op começaram por ser agentes de campo (AC) durante um período mais ou menos longo. Quanto aos sup, estes desempenharam a função op no decorrer da respetiva carreira profissional. Os ce, com estatuto-quadro, têm, na generalidade, formação em engenharia, tal como os es. Consoante a respetiva carreira profissional, nem todos os operadores possuem os mesmos anos de experiência de condução e esta experiência pode dizer respeito a procedimentos técnicos diferentes. Os op, sup, ce e es possuem uma experiência nas operações que varia, respetivamente, entre 0 e 6 anos; entre 7 e 14 anos; entre 3 e 10 anos e entre 0 e 5 anos. Os perfis de equipa, em termos de experiência nas operações da instalação, variam, por conseguinte, em função da equipa e da organização. Verificamos, todavia, que todos os três op das equipas orga-4 possuem uma experiência de condução que varia entre 3 e 7 anos, ao passo que quatro dos seis op pertencentes às equipas orga-5 não possuem qualquer experiência para além da adquirida no simulador aquando da respetiva formação. 
11 O nível de conhecimentos específicos que os operadores possuem acerca do novo reator (novos automatismos, especificidades dos sistemas elementares, novas estratégias de condução) varia ainda mais, independentemente da função desempenhada e da organização da equipa. Este nível depende de inúmeros fatores, como a frequência dos treinos no simulador, a participação na validação de novos procedimentos de condução ou interfaces de condução, etc.

\section{Etapas 1 e 2: construção da problemática}

12 A etapa 1 destinava-se a compreender as tarefas e as exigências cognitivas dos operadores que fazem parte das equipas orga-4, bem como o ambiente técnico e regulamentar dos operadores.

13 Para satisfazer este objetivo, realizou-se um estudo da documentação interna (normas, recomendações, estudos internos), bem como observações abertas e entrevistas coletivas exploratórias durante a formação das equipas nas operações em fases incidentais/acidentais nos simuladores de escala completa. Esta análise revelou, designadamente, que os operadores das equipas orga- 4 deveriam responder a exigências cognitivas mais importantes nas fases de gestão de problemas. Além disso, estes problemas resultavam, frequentemente, em concertações entre os membros da equipa.

14 A etapa 2 consistiu, por conseguinte, em investigar a gestão coletiva e dinâmica dos problemas com que se depararam as equipas orga-4, mediante a análise das interações verbais. Definimos como «problema» qualquer situação que perturbe a aplicação e/ ou a prossecução da melhor condução do processo. No total, foram observadas em tempo real e, em seguida, a posteriori através de registos áudio e vídeo, cinco simulações com uma duração de aproximadamente $2 \mathrm{~h} 30$ cada que envolveram cenários diferentes e várias equipas orga-4. Estes dados foram completados por dez horas de entrevistas coletivas pós simulação, realizadas por formadores, durante as quais foram tomadas notas sobre as dificuldades individuais e coletivas identificadas. A análise recaiu numa sequência de uma das simulações observadas que reuniu inúme ros problemas geridos pela equipa. Cada problema contido nessa sequência caracterizou-se por: 1) o respetivo objeto, 2) a quantidade e o conteúdo das concertações destinadas a gerir o problema. Uma concertação correspondia a uma sucessão de intercâmbios de informações entre um ou vários membros da equipa, 3) os membros envolvidos em cada concertação, por exemplo, a díade op-sup, a díade sup-ce ou ainda a tríade op-sup-ce. Esta análise exploratória permitiu-nos, nomeadamente, demonstrar que a gestão coletiva de um problema se traduz frequentemente por uma sequência de várias concertações muito curtas (inferiores ao minuto). Algumas gestões de problemas eram mais fracionadas ao longo do tempo. Este fracionamento pareceu, em parte, associado ao compromisso de processos cognitivos ao mais alto nível que visa a elaboração de um procedimento, a construção de uma representação ou a realização de um diagnóstico causal do estado da instalação (comportamentos com base no conhecimento). Para o tratamento destes problemas, os operadores da equipa aplicam, então, verdadeiros processos de resolução de problemas. Além disso, os operadores não parecem ter o mesmo grau de participação de acordo com a respetiva função na equipa: o op intervém mais na gestão dos problemas que têm um impacto direto e a curto prazo na condução, o ce centra-se mais na gestão antecipada dos problemas e na elaboração de objetivos, o sup proporciona informações sobre as possibilidades de implementação desses objetivos. 
15 Após estas duas etapas, o objeto da tese centrou-se nas situações de resolução coletiva de problemas ao longo dos quais os operadores devem construir uma nova representação do estado da instalação e/ou elaborar um procedimento de condução mais adequado à situação. Surgiram diversas questões destas duas etapas. Estas questões estavam relacionadas, nomeadamente, com o impacto das modalidades organizacionais da equipa sobre:

- os fluxos de comunicação - As comunicações estão repartidas de forma idêntica entre as equipas orga-4 e orga-5? Esta repartição tem algum impacto no desempenho da equipa durante a resolução de problemas?

- a participação e o tipo de contributo dos membros da equipa - A participação e o tipo de contributo dos operadores dependem da função desempenhada pelo operador? Da organização da equipa? Qual o impacto sobre o desempenho da equipa?

16 A estas modalidades organizacionais juntam-se também fatores individuais (experiência da condução, conhecimentos específicos detidos acerca do processo) não tidos em conta até ao momento, mas igualmente suscetíveis de influenciar a resolução coletiva de problemas e o desempenho da equipa.

17 A fim de investigar estas questões, decidimos convocar o quadro teórico da argumentação do qual decorre a nossa problemática (cf. secção 3).

\section{Etapas 3 e 4: exame dos fluxos de comunicação e da atividade argumentativa aquando da resolução do problema}

Os fluxos de comunicação foram amplamente estudados no passado (Barth, Schraagen, \& Schmettow, 2015; Park, Jung, \& Yang, 2012). Apenas alguns raros estudos examinaram a atividade argumentativa em situação dinâmica, no domínio da medicina (Hagler \& Brem, 2008; Lu \& Lajoie, 2008) ou ainda da aeronáutica (Bourgeon, Valot, \& Navarro, 2013). Não obstante, nenhuma delas propõe um modelo de argumentação em situação dinâmica que possa servir de referência. O objetivo principal destas duas etapas foi, portanto, elaborar e, em seguida, testar, um modelo de argumentação que combina os modelos existentes da tomada de decisão em ambiente dinâmico com o quadro teórico da argumentação.

\subsection{Método}

\subsubsection{Elaboração de um modelo de argumentação em ambiente dinâmico: o modelo ARGUinDSM}

O modelo ARGUinDSM combina o quadro teórico da argumentação (Perelman \& Olbrechts-Tyteca, 1958/2008; Toulmin, 1958/2003) com o modelo Dynamic Situation Management (DSM) de Hoc e Amalberti (1995). Este último tem a particularidade de representar as diferentes etapas do tratamento de informação como não sequenciais e de fornecer uma arquitetura cognitiva muito pormenorizada. 
Figura 2: Modelo da argumentação em situação dinâmica - ARGUinDSM (Mérand \& Darses, 2017)

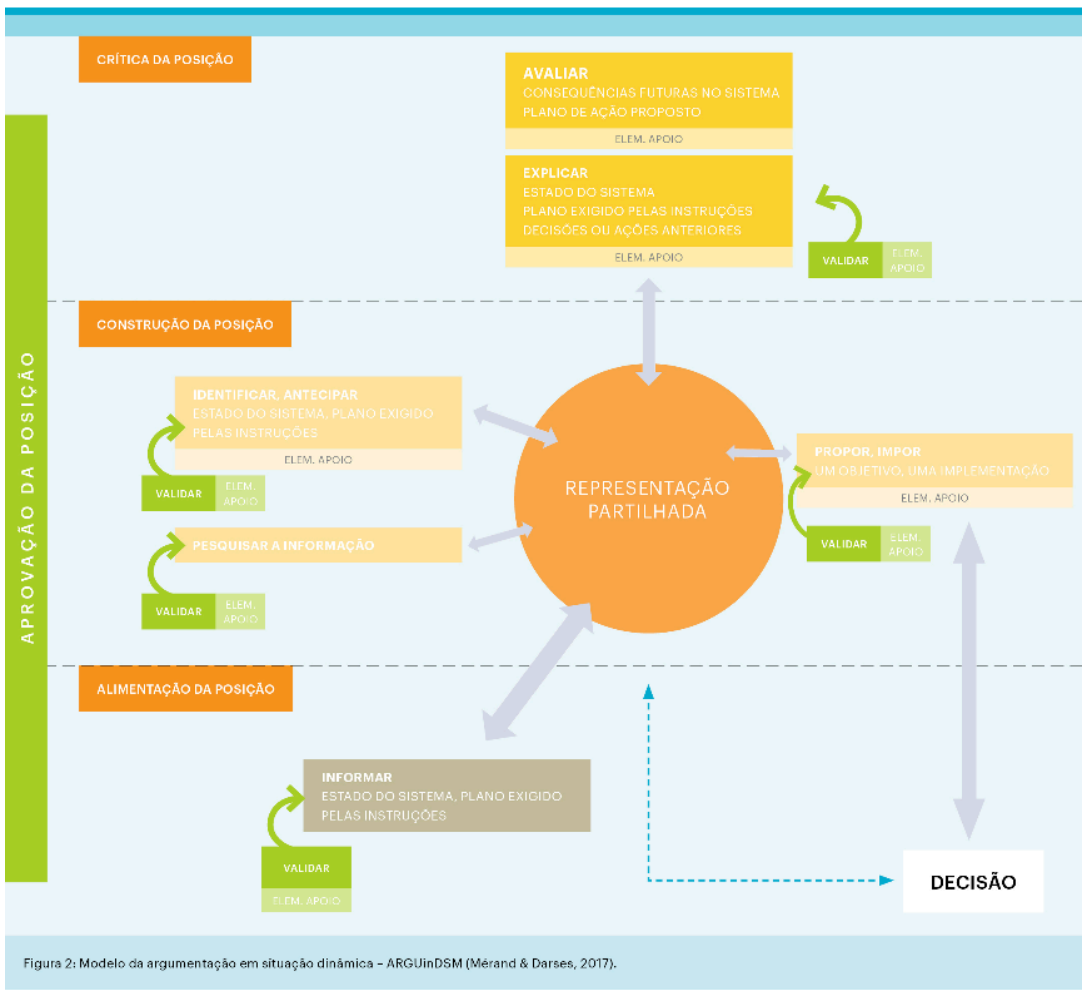

O modelo ARGUinDSM (cf. Figura 2) retoma, assim, as principais premissas do modelo DSM a fim de as transpor para a atividade argumentativa.

21 A cada nível de abstração do modelo DSM corresponde uma finalidade argumentativa específica que reúne diversas funções argumentativas. Estas funções argumentativas baseiam-se nos módulos de tratamento de informação definidos no modelo DSM, reformulando-os numa perspetiva argumentativa. O modelo apresenta, deste modo, três finalidades argumentativas, complementadas por uma quarta, transversal às outras três. Descrevem-se em seguida estas finalidades:

- Finalidade Alimentação da posição. - Reúne as funções argumentativas que visam alimentar o processo de construção conjunta do problema e as tomadas de posição de cada um. Aqui encontram-se as funções argumentativas Informar ou Solicitar informações.

- Finalidade Construção da posição. - Junta as funções argumentativas que visam construir uma representação partilhada do estado-problema e elaborar um plano de ação. Aqui encontramse, por exemplo, as funções argumentativas Identificar, Propor, ou ainda Pesquisar informações (com o objetivo de confirmar ou corroborar um diagnóstico).

- Finalidade Crítica da posição. - Junta as funções argumentativas que visam explicar e avaliar um estado-problema ou o plano de ação. Implicam deduzir com um nível mais elevado de abstração. Aqui encontram-se, por exemplo, as funções argumentativas Avaliar (positiva ou negativamente) e Explicar.

- Finalidade Aprovação da posição. - Junta as funções argumentativas que visam validar, ou invalidar, as declarações anteriormente proferidas por terceiros ou pelo próprio indivíduo. Esta finalidade permite, assim, erguer um primeiro nível explícito de articulação dos intercâmbios. Por exemplo, encontramos nesta finalidade as funções argumentativas Validar, Não validar ou Solicitar validação. 
Estas finalidades contribuem, assim, para estabelecer uma representação coletiva do estado do problema e das ações a implementar para a sua resolução.

\subsubsection{Recolha dos dados}

23 A recolha dos dados é comum às etapas 3 e 4 da tese. Incidiu sobre 12 simulações de condução incidental/acidental com uma duração de três horas, «jogadas» por três equipas orga- 4 e três equipas orga-5.

Estas 12 simulações foram observadas em tempo real e, em seguida, a posteriori, através dos registos áudio e vídeo (36 horas) da atividade na sala de controlo. As anotações em tempo real incluíam seis categorias de dados observáveis: 1) os eventos relativos ao processo; 2) as principais ações de operação; 3 ) o progresso nas instruções de operação; 4) as principais comunicações no seio da equipa e com o exterior da sala de controlo; 5) as dificuldades enfrentadas na operação; 6) as posições defendidas pelos operadores durante a gestão do problema sempre que estas fossem claramente identificáveis. Estes dados foram completados com 36 horas de entrevistas coletivas pós simulação, realizadas pela equipa de avaliação do projeto. Estas entrevistas permitiram aprofundar a nossa compreensão acerca das situações problemáticas enfrentadas pelas equipas, bem como recolher elementos relativos à representação mental e ao posicionamento dos atores face à situação e às ações previstas e realizadas para resolver os problemas. Estes dados foram, em seguida, completados por 15 entrevistas individuais realizadas $a$ posteriori com os operadores das equipas orga-5.

\subsection{Tratamento dos dados}

As comunicações verbais transmitidas aquando das simulações foram retranscritas de forma a identificar eventos-problemas. Um evento-problemas reúne todos os intercâmbios que visam a resolução de um problema específico, por exemplo, uma inadequação do procedimento prescrito da operação às especificidades da situação encontrada. Um aevento-problema poderia ser objeto de uma ou várias concertações, sucessivas ou não, entre os membros da equipa, por exemplo entre op-sup, sup-ce, op-sup-ce, etc. Cada evento-problema foi caracterizado pelo respetivo objeto e contexto, a cronologia das díades e tríades de atores envolvidos na resolução do problema, os diagnósticos efetuados e as decisões tomadas durante e/ou após o evento-problema. Cada concertação foi depois decomposta em propostas significativas, chamadas unidades de sentido. A fim de determinar os fluxos de comunicação entre os membros da equipa (etapa 3), cada unidade de sentido foi associada ao respetivo emissor e contabilizada como pertencente a uma ou outra das díades ou tríades.

O conteúdo das unidades de sentido foi depois especificado, através de um esquema de codificação predicado/argumentos elaborado a partir do modelo ARGUinDSM (etapa 4). A cada unidade de sentido corresponde, assim, uma função argumentativa que contribui para alimentar, construir, criticar ou aprovar uma posição acerca do problema. Esta função argumentativa incide num objeto passado, presente ou futuro. Pode ser encadeada com uma outra função argumentativa emitida anteriormente, já que contribui para validá-la ou invalidá-la. Podem ser igualmente fornecidos elementos de apoio para certas funções argumentativas. É por exemplo o caso para Avaliar ou Propor. 
Por último, o desempenho das equipas foi avaliado em função da precisão dos diagnósticos efetuados e da adequação das decisões tomadas durante eventos-problema. Dois especialistas avaliaram estes diagnósticos e decisões: um especialista em Fiabilidade Humana e um especialista em Ergonomia.

\subsection{Principais resultados}

As etapas 3 e 4 fornecem resultados complementares quanto à forma como os operadores discutem e articulam os respetivos intercâmbios para a resolução dos evento-problema. Estes resultados dizem principalmente respeito às funções da equipa op, sup e ce. O es está, com efeito, menos envolvido na resolução dos eventos-problema em virtude de o seu controlo independente necessitar de uma postura mais recuada em relação aos membros da equipa de operação.

\subsubsection{Uma comunicação mais distribuída nas equipas orga-5}

29 Nas equipas orga-5, a proporção de unidades de sentido emitidas pela função op é maior (op: $\mathrm{c} 2(\mathrm{ddl}=1)=31,2 \mathrm{p}<0,001)$ ao passo que a do sup, maioritária nas equipas orga-4 diminui e tende a juntar-se à do ce (sup: $\mathrm{c} 2(\mathrm{ddl}=1)=11,6 \mathrm{p}<0,001)$. 0 op dispõe de margens de manobra maiores para participar na resolução coletiva de problemas. A percentagem dos intercâmbios que reúne op-sup-ce é também superior (op-sup-ce: c2 $(\mathrm{ddl} 1)=95,97 ; \mathrm{p}<0,001)$ ao passo que os intercâmbios entre sup-ce diminuem (ce-sup:c2 $(\mathrm{ddl} 1)=48,43 ; \mathrm{p}<0,001)$ (cf. Figura 3 ).

Gráfico 1: Fluxo de comunicação, segundo a organização da equipa.

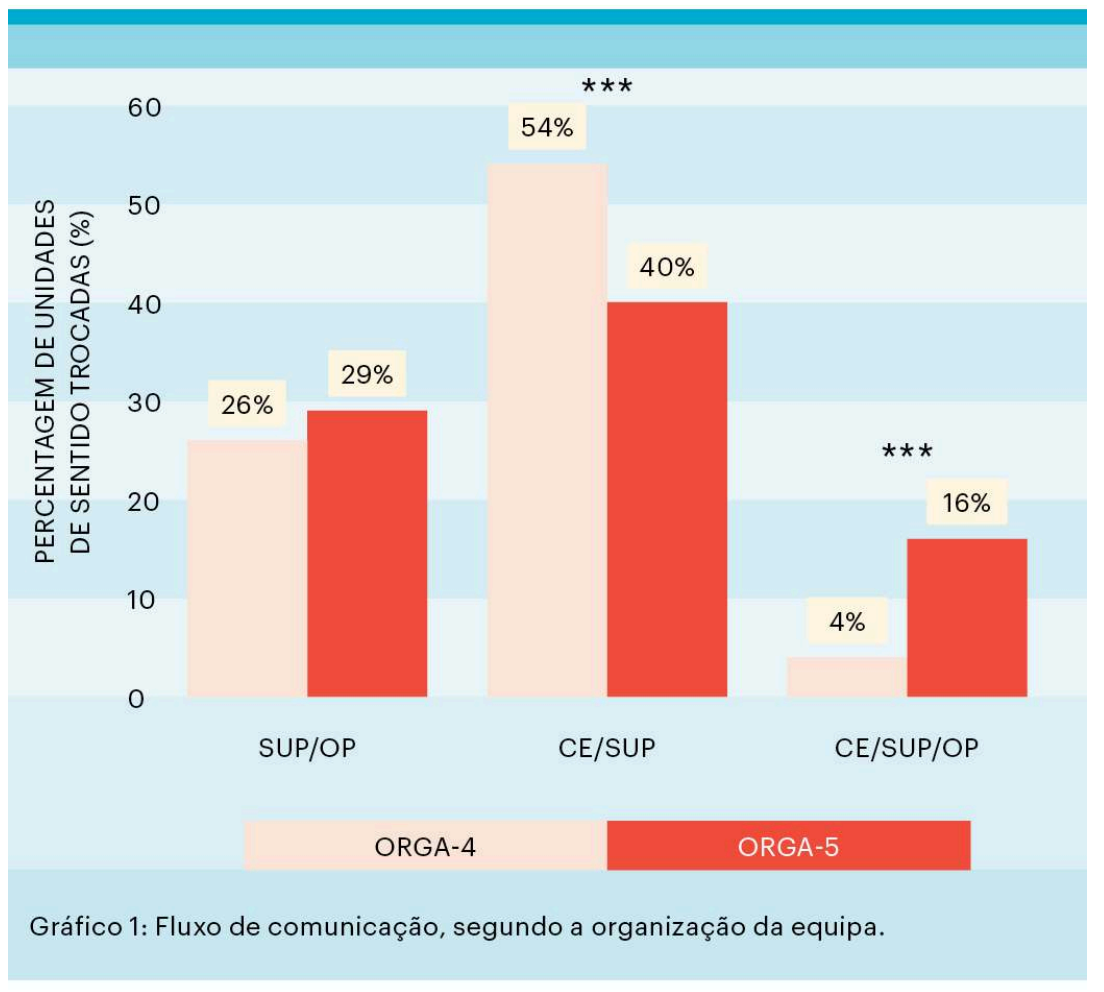

30 Os resultados revelam, assim, uma comunicação mais repartida entre os operadores que desempenham funções diferentes nas equipas de 5 operadores. 


\subsubsection{Uma mobilização mais importante da finalidade Alimentação e menos importante da finalidade Construção nas equipas orga-5}

A análise comparativa das finalidades mobilizadas pelas equipas com um desempenho maior com as mobilizadas pelas outras equipas não revela uma diferença significativa entre estes dois grupos. Não se afigura, por conseguinte, existir uma correlação direta entre a atividade argumentativa e o desempenho das equipas. Por outro lado, observam-se efeitos moderados da organização sobre os processos argumentativos. Por conseguinte, a finalidade Construção é menos mobilizada nas equipas orga-5 $(\mathrm{x} 2(\mathrm{df}=1)=$ $8,19 ; \mathrm{p}=0,004)$ ao passo que a finalidade Alimentação é mais mobilizada $(\mathrm{x} 2(\mathrm{df}=1)=4$, $29 ; p=0,038)$ (cf. Figura 4).

Figura 4: Mobilização das finalidades argumentativas, segundo a organização da equipa.

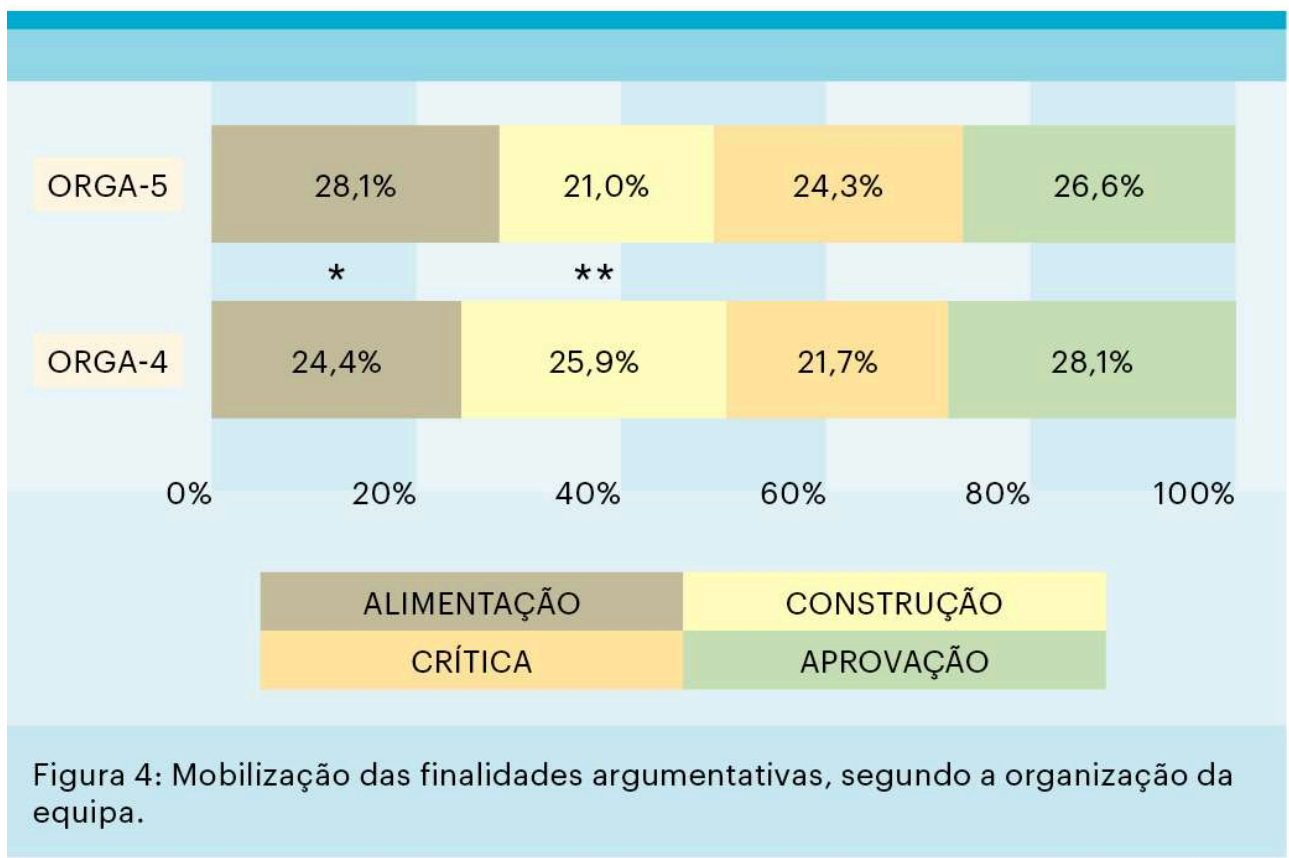

Uma análise mais aprofundada das funções argumentativas mobilizadas dentro da finalidade Construção revela que as equipas orga-5 formulam mais declarações destinadas a Pesquisar informações (SEARCH: $\mathrm{x} 2(\mathrm{df}=1)=19,42 ; \mathrm{p}<0,001)$ e menos declarações destinadas a Identificar o estado da instalação (IDEN: $\mathrm{x} 2(\mathrm{df}=1)=10,27 ; \mathrm{p}=$ $0,0013)$ e a Propor soluções para os problemas (PROP: x2 $(\mathrm{df}=1)=4,89 ; \mathrm{p}=0,027)$.

\subsubsection{Uma postura mais crítica do op nas equipas orga-5}

33 A fim de examinar a influência da organização na função argumentativa das equipas segundo a função desempenhada na equipa, distinguimos o «envolvimento» do «contributo» dos operadores. O envolvimento de um operador é definido como o seu investimento nas quatro finalidades argumentativas. O seu contributo é, por seu lado, definido como a sua participação em cada uma das finalidades argumentativas desenvolvidas pela equipa. A Figura 5 descreve a forma como estas duas noções são medidas. 
Figura 5. Medidas do envolvimento e do contributo individuais para as finalidades argumentativas

Número de unidades de sentido emitidas pelo operador com uma finalidade argumentativa

Envolvimento $=$

Número total de unidades de sentido emitidas pelo operador

Número de unidades de sentido emitidas pelo operador com uma finalidade argumentativa

Contributo $=$

Número total de unidades de sentido emitidas pela equipa com a finalidade argumentativa

Figura 5. Medidas do envolvimento e do contributo individuais para as finalidades argumentativas

Entre as funções desempenhadas na equipa, o envolvimento da função op é o que varia mais consoante a organização da equipa. Os op pertencentes às equipas orga-5 estão, assim, mais envolvidos na finalidade Crítica em $(\mathrm{x} 2(\mathrm{df}=1)=4,49 ; \mathrm{p}=0,025)$, ao passo que estão menos envolvidos na finalidade Construção $(x 2(d f=1)=4,92 ; p=0,026)$ (cf. Figura 6). 0 envolvimento do op nas finalidades Alimentação e Aprovação permanece, por seu lado, idêntica entre as organizações. 
Figura 6: Envolvimento do OP, segundo a organização da equipa.

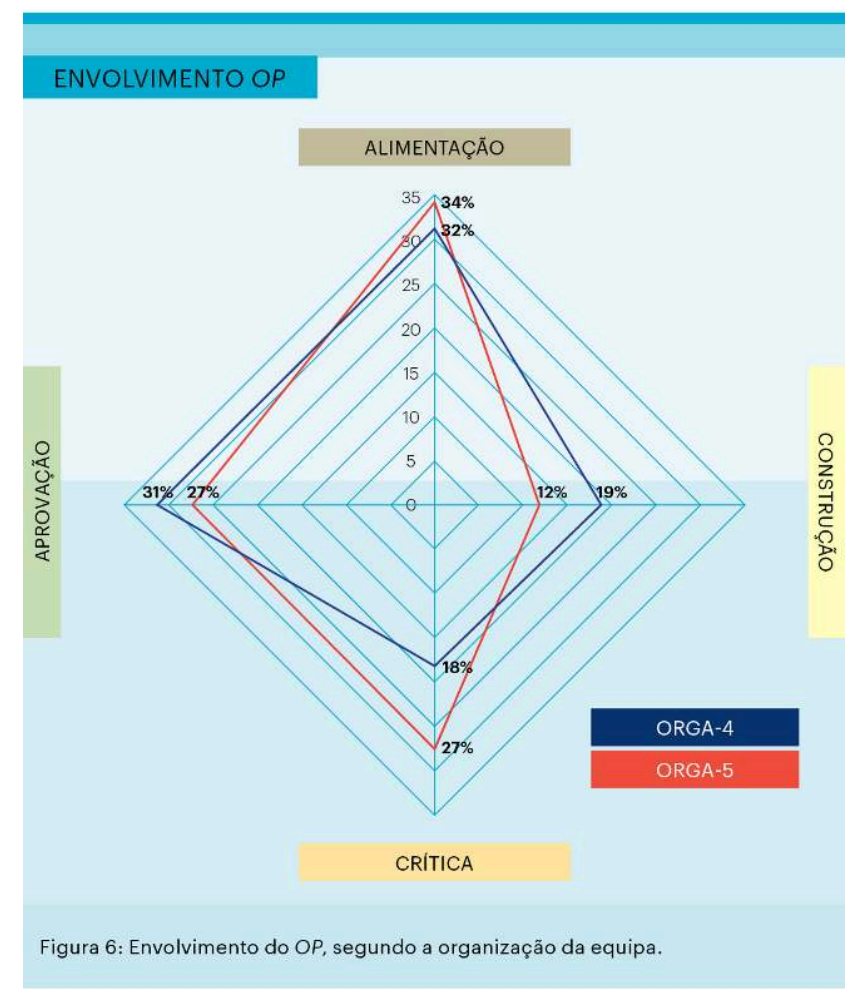

Figura 7: Contributo dos operadores para a finalidade Crítica, segundo a respetiva função na equipa

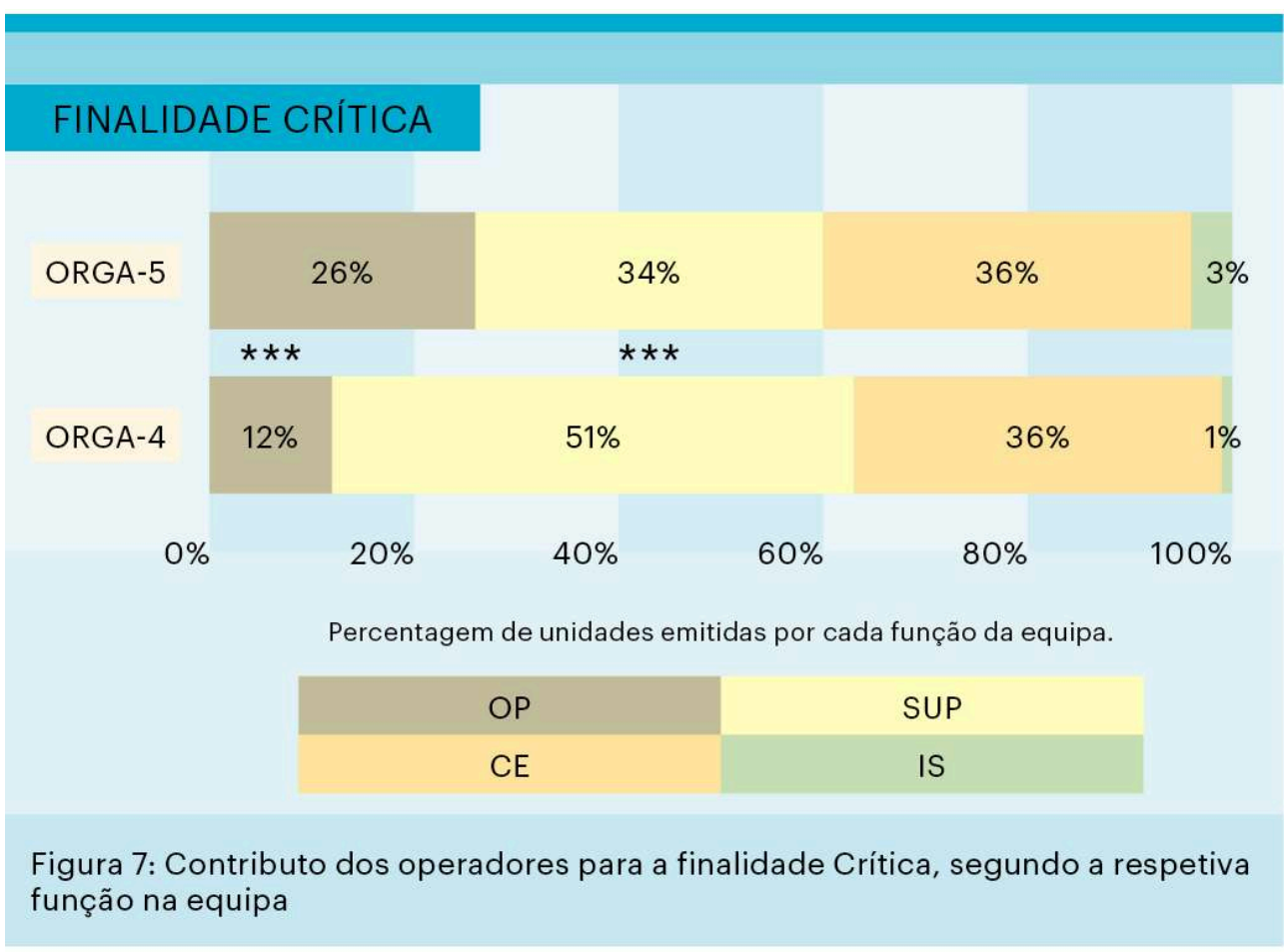

No que respeita ao contributo individual para as finalidades argumentativas, as diferenças mais significativas são relativas à finalidade Crítica, nomeadamente quanto ao op e ao sup (cf. Figura 7). 0 contributo do op para esta finalidade é maior nas equipas 
orga-5 $(\mathrm{x} 2(\mathrm{df}=1)=17,42 ; \mathrm{p}<0,001)$. Ele formula, assim, mais avaliações e explicações acerca do estado do problema e/ou as soluções para a sua resolução. Por outro lado, o contributo do sup para esta finalidade diminui, ao passo que era amplamente maioritária nas equipas orga-4 $(\mathrm{x} 2(\mathrm{df}=1)=15,71 ; \mathrm{p}<0,001)$.

Apesar destas evoluções do envolvimento e do contributo dos operadores para as finalidades argumentativas, não se observou qualquer efeito da organização na qualidade das decisões e dos diagnósticos efetuados pela equipa.

\section{Discussão}

\subsection{Contributo empírico}

De um ponto de vista empírico, as nossas análises permitiram mostrar uma comunicação mais repartida entre os membros das equipas orga-5. É muito provável que a carga de trabalho da função op, repartida por dois membros nas equipas orga-5, permita aos operadores que desempenham essa função: i) ter maior disponibilidade para participar na resolução de problemas; ii) adotar uma postura mais crítica que revela mais distância face à situação. Apesar de estes efeitos não terem afetado o desempenho das equipas nas situações observadas, consideramos que são desejáveis e favoráveis para a fiabilização das decisões na sala de controlo.

As equipas orga-5 parecem igualmente mostrar uma melhor compreensão dos problemas. Teriam maior margem de manobra para alimentar a resolução de problemas e, em seguida, para a construção de uma representação de problema e do plano de ação através de comportamentos de pesquisa de informações. As identificações seriam mais precisas e as propostas mais adequadas, não necessitando de reformulação posterior. 0 tempo de construção de uma representação do problema e de um plano de ação diminuiria. Estas interpretações são corroboradas por observações mais qualitativas que mostrem equipas orga-5 mais serenas na sala de controlo.

Por outro lado, não se observou qualquer ligação entre a atividade argumentativa desenvolvida e o desempenho das equipas. Este resultado pode explicar-se por diversos fatores. Por um lado, a dimensão da amostra restringe o âmbito do estudo comparativo entre as equipas. Estas seis equipas constituem, todavia, uma amostra representativa das futuras equipas de operação. Por outro lado, existem outros fatores que podem explicar o desempenho. Por exemplo, a experiência e o nível de conhecimentos específicos sobre o novo processo que os operadores possuem permitiram proporcionar mecanismos de regulação coletiva do desempenho dentro das equipas. As nossas tentativas de examinar o efeito destes fatores foram particularmente limitadas pela dimensão da amostra. Este ponto mereceria ser investigado quanto aos efetivos mais importantes.

\subsection{Contribuição teórica}

A principal contribuição teórica da tese consiste na elaboração do modelo ARGUinDSM que concetualiza a atividade argumentativa em situação dinâmica. Propostos a partir da sua aplicação, estes trabalhos de tese demonstraram que se pode operacionalizar em diálogos reais, em situações ecológicas de condução de um sistema complexo de alto risco. O modelo ARGUinDSM oferece, deste modo, novas perspetivas para a 
compreensão dos processos de decisão na sala de controlo e para a melhoria da fiabilização destes processos. Por um lado, a sua aplicação na operação de uma instalação nuclear ultrapassa o âmbito das situações acidentais. Com efeito, os operadores resolvem também problemas em modo de funcionamento normal. Estes problemas podem mesmo por vezes revelar-se mais delicados, na medida em que as instruções operacionais são menos rigorosas e detalhadas nessas situações. Por outro lado, o modelo ARGUinDSM pretende ser generalizável a outros ambientes dinâmicos em que as margens temporais sejam suficientemente amplas para permitir uma concertação dos operadores aquando da atividade de resolução de problemas.

\section{BIBLIOGRAFIA}

Baker, M. J. (1999). Argumentation and constructive interaction. In P. Coirier \& J. Andriessen (Eds.), Foundations of Argumentative Text Processing (pp. 179-202). Amsterdam: University of Amsterdam Press.

Barth, S., Schraagen, J. M. \& Schmettow, M. (2015). Network measures for characterising team adaptation processes. Ergonomics, 58(8), 1287-1302. https://doi.org/

10.1080/00140139.2015.1009951

Bourgeon, L., Valot, C., \& Navarro, C. (2013). Communication and Flexibility in Aircrews Facing Unexpected and Risky Situations. The International Journal of Aviation Psychology, 23(4), 289-305. https://doi.org/10.1080/10508414.2013.833744

Breton, P. (2006). L'argumentation dans la communication. Paris, France: Editions La Découverte.

Cannon-Bowers, J. A., Salas, E., \& Converse, S. (1993). Shared mental models in expert team decision making. In N. J. Castellan (Ed.), Individual and group decision making: Current issues. Hillsdale, N: Erlbaum.

Champaud, C. (1994). L'argumentation. Psychologie Française, 39(2), 193-203.

Darses, F. (2006). Analyse du processus d'argumentation dans une situation de reconception collective d'outillages. Le travail humain, 69(4), 317-347. https://doi.org/10.3917/th.694.0317

De La Garza, C., Labarthe, J.-P., \& Graglia, L. (2012). The contribution of ergonomics to risk analysis in the design process: the case of a future control room. Work: A Journal of Prevention, Assessment and Rehabilitation, 41 Suppl 1, 730-736. https://doi.org/10.3233/WOR-2012-0233-730

Hagler, D. A. \& Brem, S. K. (2008). Reaching agreement: Thestructure \& pragmatics of critical care nurses' informal argument. Contemporary Educational Psychology, 33(3), 403-424. https://doi.org/ 10.1016/j.cedpsych.2008.05.002

Hoc, J.-M. \& Amalberti, R. (1995). Diagnosis: Some theoretical questions raised by applied research. Cahiers de Psychologie Cognitive, 14(1), 73-101.

Klein, G. \& Klinger, D. (1991). Naturalistic Decision Making. Human Systems Information Analysis Center Gateway, XI(3), 16-19. 
Labarthe, J.-P. \& De La Garza, C. (2011). The human factors evaluation program of a control room: The French EPR approach. Human Factors and Ergonomics in Manufacturing \& Service Industries, 21(4), 331-349. https://doi.org/10.1002/hfm.20227

Lu, J. \& Lajoie, S. P. (2008). Supporting medical decision making with argumentation tools. Contemporary Educational Psychology, 33(3), 425-442. http://dx.doi.org/10.1016/j.cedpsych. 2008.05.005

Mérand, J. \& Darses, F. (2017). ARGUinDSM - A model of argumentation in team problem-solving situation: An application to nuclear control room teams. Presented at the 13th International Conference on Naturalistic Decision Making, Bath, UK.

Nussbaum, E. M. (2008). Collaborative discourse, argumentation, and learning: Preface and literature review. Contemporary Educational Psychology, 33(3), 345-359. DOI: 10.1016/j.cedpsych. 2008.06.001

Oléron, P. (1996). L'argumentation. (4e éd). Paris, France : Presses universitaires de France.

Park, J., Jung, W., \& Yang, J.-E. (2012). Investigating the effect of communication characteristics on crew performance under the simulated emergency condition of nuclear power plants. Reliability Engineering \& System Safety, 101, 1-13. https://doi.org/10.1016/j.ress.2012.01.003

Perelman, C. \& Olbrechts-Tyteca, L. (1958/2008). Traité de l'argumentation. La nouvelle rhétorique. 6ème édition. (6e éd). Bruxelles, Belgique : Editions de l'Université de Bruxelles.

Rasmussen, J. (1986). Information Processing and Human-Machine Interaction: An Approach to Cognitive Engineering. New York, NY, USA: Elsevier Science Inc.

Rieke, R. D., Sillars, M. O., \& Peterson, T. R. (2005). Argumentation and critical decision making. (6e éd). Pearson.

Toulmin, S. E. (1958/2003). The uses of argument (2e éd.). New York, USA: Cambridge University Press. https://doi.org/10.1017/CB09780511840005

Vicente, K. J., Mumaw, R. J., \& Roth, E. M. (2004). Operator monitoring in a complex dynamic work environment: a qualitative cognitive model based on field observations. Theoretical Issues in Ergonomics Science, 5(5), 359-384. https://doi.org/10. 1080/14039220412331298929

\section{AUTOR}

\section{JOHANNA MÉRAND}

Institut de Recherche Biomédicale des Armées

91223 Brétigny sur Orge France

merand.johanna@gmail.com 